\title{
Variation of Temperatures of Discharge with a Liquid Electrode on the Basis of Distilled Water near the Ignition Threshold Mode
}

\author{
Livia Mesarosh $^{1^{*}}$, Mihailo Chuchman ${ }^{2}$, Aleksandr Shuaibov ${ }^{2}$ \\ ${ }^{1}$ Ferenc Rakoczi II Transcarpathian Hungarian Institute, Berehovo, Ukraine \\ ${ }^{2}$ Uzhgorod National University, Uzhgorod, Ukraine \\ Email: liviamesarosh@gmail.com
}

\begin{abstract}
Emission spectra of glow discharge with copper and a liquid electrode on the basis of distilled water in the range of wavelengths of 200-700 nm are investigated. For discharge currents from $12 \mathrm{~mA}$ to $32 \mathrm{~mA}$ the values of the electron, vibrational and rotational temperatures are obtained.
\end{abstract}

Keywords: Electron, vibrational and rotational temperatures, glow discharge, ignition threshold mode, distilled water.

\section{Introduction}

The glowing discharge of atmospheric pressure in the air between the metal anode and the liquid cathode is simply to realize and control the parameters of the plasma. For glow discharge, where not expensive initial materials are used, therefore, there is a considerable amount of practical applications in plasma chemistry for the synthesis and conversion of chemical compounds in the volume of discharge and on the surface of the liquid. It also used in ecology for water and air purification and for the synthesis of nanoparticles, in plasma physics, for spectroscopic analysis of solutions [1-4]. Such discharge is unique as object for a comprehensive study of physical and chemical phenomena $[5,6]$.

The results of the averaged plasma parameters study near the ignition threshold are fewness, although the effect on the chemical composition of liquid is small. A significant improvement in the plasmachemical reactions has a current threshold. The plasma composition and temperature are various in different spatial regions. So the temperature averaged by volume and calculated using the emission of different particles differs $[7,8]$. In addition, the plasma parameters are sensitive to the spatial and electrical characteristics of the discharge and to the properties of the liquid electrode. The ratios of vibrational and rotational temperatures are as follows: $\mathrm{T}_{\mathrm{r}}(\mathrm{OH})>\mathrm{T}_{\mathrm{r}}\left(\mathrm{N}_{2}\right)$, and $\mathrm{T}_{\mathrm{r}}<\mathrm{T}_{\mathrm{v}}[9]$.

We investigated of electron temperature and the rotational and vibrational temperatures of discharge plasma above the distilled water in ignition threshold mode, when electrochemical processes just begin to manifest themselves in plasma and it is possible to control the effect on the liquid.

\section{Experimental Setup and Calculation Method}

A glow discharge in free air was ignited over the surface of the distilled water in a Plexiglas cuvette. The test bench diagram is presented in [10]. The metal anode placed over the surface of distilled water in air was made in the form of a copper needle $2 \mathrm{~mm}$ in diameter. The copper anode was attached in a special mobile device to vary the spacing between the needle tip and the distilled water surface from 1 to $12 \mathrm{~mm}$. The second copper electrode in the form of a plate was situated in the distilled water. The distance between the upper plate metal surface and the distilled water surface could be varied from 1 to $10 \mathrm{~mm}$. The container volume was about $10^{3} \mathrm{~cm}^{3}$. The main experiments were carried out at an anode tip-distilled water surface spacing of $7 \mathrm{~mm}$ and a water thickness of $5 \mathrm{~mm}$ over the metal cathode surface. A high-voltage rectifier with the peak output characteristics (voltage $\mathrm{U}=1-25 \mathrm{kV}$; current $I=$ 1-100 mA) was used to ignite a glow discharge. A ballast resistance of $\mathrm{R}=434 \mathrm{k} \Omega$ was used to stabilize the glow discharge [11]. 
Plasma emission was analyzed in the spectral area of 200-700 nm. Emission intensities were corrected for the detector + monochromator spectral response. The measurement system consists of an MDR-2 monochromator (1200 grooves/mm), FEU-106 photomultiplier and a KSP-4 recorder. The intensity was measured with an accuracy of no less than $10 \%$. The spectra were interpreted using the data [12]. Knowing the spectral sensitivity of the photomultiplier can compare the relative intensities of the spectral lines. From the relative emission intensities and spectroscopic constants of these transition [11], one can calculate the populations of the excited states [13]:

$$
\mathrm{N}_{m}=\lambda_{m i} I_{m i} / A_{m i}
$$

where $\mathrm{N}_{m}$ is the concentration of particles in the $m$ th excited state, $I_{m i}$ is the intensity of the emission corresponding to the transition from the $m$ th to the $i$ th energy level, $A_{m i}$ is the transition probability, and $\lambda_{m i}$ is the wavelength of the spectral line (band). The radiation of the hydrogen atoms, hydroxyl and nitrogen molecules were used to constructions of Boltzman distribution and determination of temperatures:

$$
T=\Delta E / \Delta \ln (\mathrm{N} / g) \text {. }
$$

where $g$ is the statistical weight, $\Delta E$ - energy difference of excited states. Constants for calculation are given in [14-16].

\section{$3 \quad$ Results}

The interpretation of most intensive part of plasma emission is presented in fig. 1. Most intensive is a radiation of molecules of nitrogen and hydroxyl. The radiation of spectral lines of copper atom on the wavelength of $324.8 \mathrm{~nm} \mathrm{Cu} \mathrm{I}$, the radiation of $\gamma$-bands of No molecule on the transition of $247.8 \mathrm{~nm}$ ${ }^{2} \Sigma \rightarrow{ }^{2} \Pi(0 ; 2)$ and the radiation of hydrogen at $656.2 \mathrm{~nm} \mathrm{H}_{\alpha}$ are with maximal intensity [17].

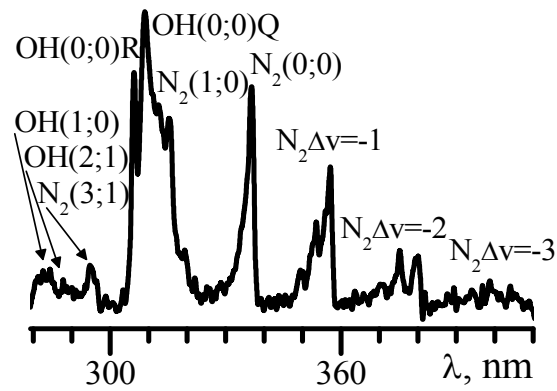

Figure 1. Spectrum of radiation of glow-discharge with a liquid electrode on the basis of the distilled water at the current of $17 \mathrm{~mA}$. The bands show the vibration transitions between electron states $\mathrm{A}^{2} \Sigma+-\mathrm{X}^{2} \Pi_{\mathrm{i}}$ for $\mathrm{OH}$ and $\mathrm{C}^{3} \Pi_{\mathrm{u}^{-}}$ $\mathrm{B}^{3} \Pi_{\mathrm{g}}$ for $\mathrm{N}_{2}$.

Fig. 2 presents the dependences of electron temperature variation on discharge current. From the analysis of fig. 2 evidently, the higher electron temperature of discharge plasma for the cathode on the basis of distilled water was observed at the discharge current $12 \mathrm{~mA}$, immediately after the ignition of discharge, and with current rise to $32 \mathrm{~mA}$ gradually fell [18]. The value of $\mathrm{T}_{\mathrm{e}}$ was in the range (0.31-0.22) $\mathrm{eV}$.

Fig. 3 presents the dependences of change vibrational temperature from discharge current determined using radiation of nitrogen and hydroxyl molecules. The vibrational temperature of the discharge plasma is determined for $\mathrm{N}_{2}$ increases $(0.15-0.33) \mathrm{eV}$ with increasing of discharge current. The vibrational temperature of the discharge plasma is determined by $\mathrm{OH}$ radiation has a specific behaviour, after a sharp decrease (0.4-0.37) eV there is a repeated growth to $0.4 \mathrm{eV}$ and a decrease to $0.35 \mathrm{eV}$.

Fig. 4 presents the dependence of rotational temperature is determined using radiation of nitrogen and hydroxyl molecules on discharge current. The rotational temperature determined by the radiation of $\mathrm{OH}$ decreases from 0.32 to $0.26 \mathrm{eV}$. The rotation temperature of nitrogen molecules increases from 0.034 to $0.043 \mathrm{eV}$. 


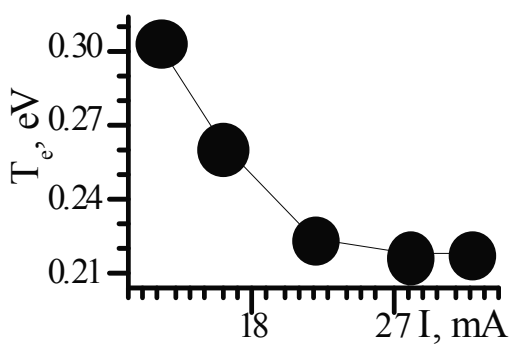

Figure 2. Dependence of electron temperature on discharge current.

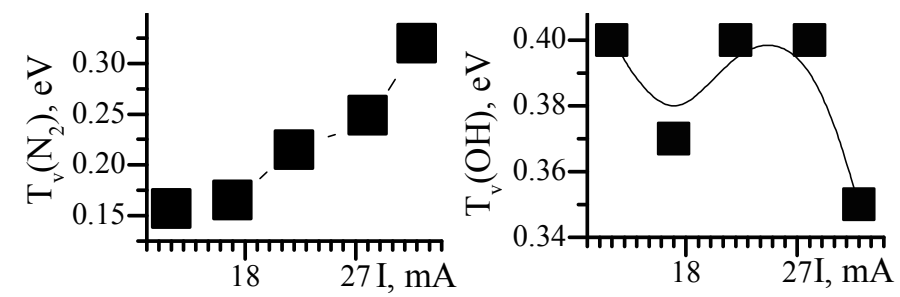

Figure 3. The dependence of vibrational temperature of nitrogen molecules and hydroxyl radicals on discharge current.
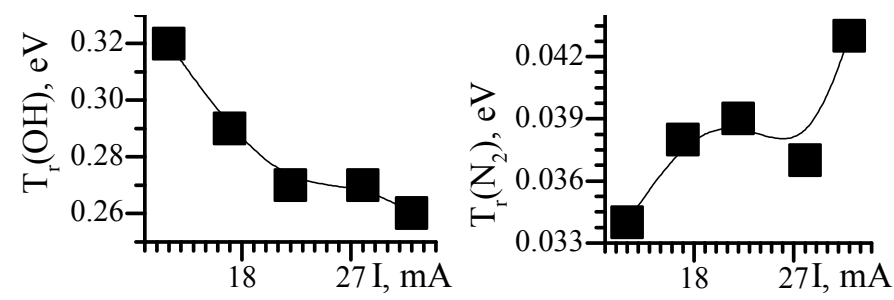

Figure 4. The dependence of the rotational temperature of $\mathrm{OH}$ and $\mathrm{N}_{2}$ molecules on the current of a glow discharge with a liquid electrode on the basis of distilled water.

\section{Discussion}

The most intensive is emission of $\mathrm{N}_{2}$ molecules and $\mathrm{OH}$ radicals. The hydroxyl emission becomes dominant when current grows. Plasma radiation contains small intensity of $\mathrm{Cu}, \mathrm{H}$ and $\mathrm{NO}$ emission. The discharge is ignited in the air and is localized over the water. If current increases then plasma occupies the interelectrode distance at first, and then increases in volume. The form of plasma formation varies from cone to cylinder, and then to oval. The action of the plasma on water causes it to evaporate in a discharge gap and decomposes it into $\mathrm{H}$ and $\mathrm{OH}$. Growth of concentration of $\mathrm{OH}$ leads to its domination in radiation. The destruction of the anode due to the action of electrons and electronegative molecules leads to the appearance of copper radiation. The plasmochemical processes in the mixture of nitrogen molecules, water and the products of their decomposition lead to the appearance of molecules NO. The burning of the discharge requires the constant formation of charged particles in the most highenergetic cathode layer, and the growth of the current leads to an increase in their amount, increasing the effect on the surface of water. Thus, molecules with small ionization energies that appear in plasma at current growth will supplant nitrogen molecules from high-energy layers of the plasma [19]. Near the electrode, the brightness of the plasma of the discharge correlates with the electrical characteristics [20]. In the distance from the surface of the liquid, a prolonged afterglow appears in the peripheral layers of the discharge, where the temperature is lower. The study of discharge characteristics above the surface of the water under atmospheric air pressure in [21] makes it possible to develop lamps on nitrogen molecules and water vapour decomposition products [22], and also indicates the optimization of processes that initiate decomposition of pollution. 
The temperature is determined by the radiation of various components of the plasma will also reflect the described specificity. That is, the temperature will depend on the mechanism of the appearance of particles and their spatial localization in plasma, ionization energy. With the growth of the current, the gas mixture is enriched with water, products of its decomposition and chemical reactions. Along with the increase in volume and the change in the shape of the plasma, the electronic temperature drops. This correlates with the decrease of the cathode voltage drop and the growth of the plasma volume [19]. Vibrational temperature shows that up to current of $25 \mathrm{~mA}$ the hydroxyl is situated in the most energetic plasma layer and the distribution of intensity indicates the gradual dominance of its radiation in the whole plasma [23]. With increasing current, the vibrational temperature of nitrogen approaches to the vibrational temperature of hydroxyl [23], which is evenly distributed over the entire plasma volume. The rotational temperature of nitrogen at low currents shows the gas temperature (384-488 K or 111$215 \mathrm{C}$ ), it is insignificantly higher then boiling point of water. When the discharge becomes the elliptical form, the rotational temperature begins to grow. The behaviour and the value of vibrational temperature of hydroxyl are like the behaviour and the value of the electron temperature determined on the basis the radiation of hydrogen. In the similar case of dependence of intensity on the current it can show the same conditions at which they are formed due to the disintegration of water molecules.

The average value of $T_{e}$ according to different authors [7-9, 24-26] is in limits of $0.2-0.5 \mathrm{eV}$. As the discharge gap increases, the average temperature increases. The highest temperature (up to $0.7 \mathrm{eV}$ ) is in the cathode region. The average values of rotational and vibrational temperatures are in the range of $0.15-0.45 \mathrm{eV}$.

\section{Conclusions}

The plasma radiation shows molecules of $\mathrm{N}_{2}, \mathrm{OH}, \mathrm{NO}$, and atoms of $\mathrm{H}, \mathrm{Cu}$. Using the $\mathrm{N}_{2}, \mathrm{OH}$ and $\mathrm{H}$ emissions the electron, vibrational and rotational temperatures of plasma are obtained. The temperature depending on the formation process, the concentration, the position and the ionization energy of plasma components is discussed. The values of the electron, vibrational and rotational temperatures in the 12-32 $\mathrm{mA}$ range of discharge currents vary within limits: $\mathrm{T}_{\mathrm{e}}(\mathrm{H})=(0.31-0.22) \mathrm{eV}, \mathrm{T}_{v}\left(\mathrm{~N}_{2}\right)=(0.15-0.33) \mathrm{eV}$, $\mathrm{T}_{v}(\mathrm{OH})=(0.4-0.35) \mathrm{eV}, \mathrm{T}_{\mathrm{r}}\left(\mathrm{N}_{2}\right)=(0.034-0.043) \mathrm{eV}, \mathrm{T}_{\mathrm{r}}(\mathrm{OH})=(0.32-0.26) \mathrm{eV}$.

\section{References}

1. Q. Chen, T. Kaneko, R. Hatakeyama, "Reductants in gold nanoparticle synthesis using gas-liquid interfacial discharge plasmas," Applied Physics Express, vol. 5, 086201-3p, 2012.

2. M. Klas, S. Matejcik, M. Radmilovic-Radjenovic, B. Radjenovic, "Electrical breakdown and volt-ampere characteristics in water vapor in microgaps," EPL, vol. 99, 57001-4p, 2012.

3. Plasma chemistry and catalysis in gases and liquids, edited by V.I. Parvulescu, M. Magureanu, P. Lukes. Weinheim: Wiley-VCH Verlag GmbH \& Co. KgaA, 2012.

4. F. Al-Momani, E. Touraud, J.R. Degorce-Dumas, J. Roussy, O. Thomas, "Biodegradability enhancement of textile dyes and textile wastewater by VUV photolysis," J. Photochem. Photobiol. A: Chem., vol. 153, no. 1, pp.191-197, 2002.

5. Z. Kozáková, "Electric discharges in water solutions," Ph.D. thesis, Brno University of Technology Faculty of Chemistry, Brno, 2011.

6. I. Levchenko, K. Bazaka, O. Baranov, R.M. Sankaran, A. Nomine, T. Belmonte, S. Xu, "Lightning under water: Diverse reactive environments and evidence of synergistic effects for material treatment and activation," Applied Physics Reviews, vol. 5, 021103 -31p, 2018.

7. P. Jamroz, W. Zyrnicki, "Spectroscopic characterization of miniaturized atmospheric-pressure dc glow discharge generated in contact with flowing small size liquid cathode," Plasma Chem. Plasma Process., vol. 31, pp. 681696, 2011.

8. P. Mezei, T. Cserfalvi, "A critical review of published data on the gas temperature and the electron density in the electrolyte cathode atmospheric glow discharges," Sensors, vol. 12, pp. 6576-6586, 2012.

9. M.R. Webb, F.J. Andrade, G. Gamez, R. McCrindleb, G.M. Hieftje, "Spectroscopic and electrical studies of a solution-cathode glow discharge," J. Anal. At. Spectrom., vol. 20, pp. 1218-1225, 2005. 
10. L.V. Mesarosh, O.K. Shuaibov, M.P. Chuchman, "Investigation of glow discharge over the surface of distilled water," Scientific Herald of Uzhhorod University: Series Physics, no. 32, pp. 82-88, 2012.

11. A.K. Shuaibov, M.P. Chuchman, L.V. Mesarosh, "Electrical characteristics of a glow discharge in air over the surface of aluminum sulfate aqueous solution," Surface Engineering and Applied Electrochemistry, vol. 54, no. 3, pp. 267-272, 2018.

12. P.L. Smith, C. Heise, J.R. Esmond, R.L. Kurucz, Atomic spectral line database from CD-ROM 23 of R.L. Kurucz. Cambridge: Smithsonian Astrophysical Observatory, 1995. http://cfa-www.harvard.edu/amp.

13. Plasmas diagnostics, ed. by W. Lochte-Holtgreven. New York: American Elsevier, 1968.

14. N.E. Kuz'menko, L.A. Kuznetsova, Y.Y. Kuzyakyn, Factors of Frank-Condon for diatomic molecules. Moscow: Moscow State University, 1984.

15. Gr'egoire de Izarra, Jean-Marie Cormier, "New methods to determine temperatures from UV OH spectrum" $J$. Phys. D: Appl. Phys., vol. 46, 105503-17p, 2013.

16. A.A. Radtsyh, B.M. Smyrnov, Parameters of atoms and atomic ions. Moscow: Enerhoatomyzdat, 1986.

17. L.V. Mesarosh, A.K. Shuaibov, Relevant Problems in Quantum Physics. Practical Manual. Uzhgorod: Goverla, 2015.

18. L.V. Mesarosh, A.K. Shuaibov, M.P. Chuchman, "The investigation of electrons temperature in glow-discharge above the surface of the distilled water," Proc. of the VIII International scientific conference "Electronics and Applied Physics", Taras Shevchenko National University of Kyiv. Faculty of Radiophysics. Ukraine, 2012, pp. 146-147.

19. A.K. Shuaibov, M.P. Chuchman, L.V. Mesarosh, "Characteristics of a glow discharge in atmospheric pressure air over the water surface," Technical Physics, vol. 59, no. 6, pp. 847-851, 2014.

20. V.B. Yuferov, E.V. Mufel, V.I. Tkachov, S.V. Sharyi, A.N. Shapoval, "On some features of plasma discharge above water surface," Ukr. J. Phys., vol. 55, no. 6, pp. 671-676, 2010.

21. Ya.I. Kornev, N.A. Yavorovsky, G.F. Ivanov, G.G. Saveliev, T.V. Shamanskaya, "The use of emission spectra to study the characteristics of a barrier discharge in water-air environment," Bulletin of the Tomsk Polytechnic University, vol. 306, no. 5, pp. 78-82, 2003.

22. A.A. General, V.A. Kelman, Yu.V. Zhmenyak, Yu.O. Shpenik, "A UV source on hydroxyl molecules operating in a pulsed-periodic mode," Instruments and Experimental Techniques, vol. 53, no. 4, pp. 558-561, 2010.

23. M.P. Chuchman, L.V. Mesarosh, A.K. Shuaibov, V.V. Kiris, N.V. Tarasenko, "Emission spectra of glow discharge in the air with an electrode on the basis of distilled water," Journal of Applied Spectroscopy, vol. 83, no. 5, pp. 742-746, 2016.

24. A. Choukourov, A.S. Manukyan, D.A. Shutov, V.V. Rybkin, "Physico-chemical properties of dc current discharge plasma with liquid cathode," Izv. Vyssh. Uchebn. Zaved. Khim. Khim. Tekhnol., vol. 59, no. 12, pp. 416, 2016.

25. P. Bruggeman, J.J. Liu, J. Degroote, M.G. Kong, J. Vierendeels, C. Leys, "DC excited glow discharges in atmospheric pressure air in pin-to-water electrode systems," J. Phys. D: Appl. Phys., vol. 41, no. 7, 215201-11p, 2008.

26. P. Mezei, T. Cserfalvi, "Electrolyte cathode atmospheric glow discharges for direct solution analysis," Applied Spectroscopy Reviews, vol. 42, pp. 573-604, 2007. 